\title{
Low plasma magnesium concentration and future abdominal aortic calcifications in moderate chronic kidney disease
}

\author{
Anique D. ter Braake ${ }^{1}$, Larissa P. Govers ${ }^{1}$, Mieke J. Peeters ${ }^{2}$, Arjan D. van Zuilen ${ }^{3}$, Jack F. M. Wetzels²,
} Peter J. Blankenstijn ${ }^{3}$, Joost G. J. Hoenderop ${ }^{1}$, Jeroen H. F. de Baaij ${ }^{1}$, Jan A. J. G. van den Brand ${ }^{2 *}$ (D) and For the MASTERPLAN study group

\begin{abstract}
Background: Higher plasma magnesium concentrations are associated with reduced cardiovascular disease risk in chronic kidney disease (CKD) patients. The importance of plasma magnesium concentration for vascular calcification in earlier stages of CKD remains underexplored. This study investigated whether plasma magnesium is a determinant for the presence and severity of vascular calcification in moderate CKD.

Methods: Retrospective analysis was performed using abdominal aortic calcification (AAC) scores in 280 patients with stage 3 and 4 CKD enrolled in the MASTERPLAN trial. Lateral abdominal $X$-ray was used to evaluate AAC. Plasma magnesium concentration were measured over time. A zero-inflated Poisson model determined the association between plasma magnesium concentration and AAC.

Results: 79 out of 280 patients did not have AAC, and in patients with AAC the median calcification score was 3.5 (interquartile range: $0.0-8.6$ ). The mean plasma magnesium concentration was $0.76 \pm 0.10 \mathrm{mmol} / \mathrm{L}$ at baseline. A 0.1 $\mathrm{mmol} / \mathrm{L}$ higher plasma magnesium concentration was associated with lower AAC of 0.07 point $(95 \% \mathrm{Cl}-0.28-$ 0.14). A $0.1 \mathrm{mmol} / \mathrm{L}$ higher plasma magnesium lowered the odds of detecting any $\mathrm{AAC}$ by $30 \%(\mathrm{OR}=0.63 ; 95 \% \mathrm{Cl}$ 0.29-1.37). After 1 year and 4 years (at time of $X$-ray) of follow-up this association was attenuated $(\mathrm{OR}=0.93 ; 95 \% \mathrm{Cl}$ $0.61-1.43$ and $0.93 ; 95 \% \mathrm{Cl} 0.60-1.45$, respectively). None of these associations reached statistical significance.
\end{abstract}

Conclusions: Plasma magnesium concentration at baseline is not associated with the risk for future AAC. Interventions increasing magnesium to avoid vascular calcification may have greatest potential in early CKD stages prior to onset of vascular calcification.

Keywords: Abdominal aortic calcification score, Chronic kidney disease, Magnesium, Vascular calcification

\footnotetext{
* Correspondence: Jan.vandenBrand@radboudumc.nl

${ }^{2}$ Department of Nephrology, Radboud Institute for Health Sciences, Radboud

University Medical Center, PO box 9101, 6500, HB, Nijmegen, The Netherlands

Full list of author information is available at the end of the article
}

(C) The Author(s). 2021 Open Access This article is licensed under a Creative Commons Attribution 4.0 International License, which permits use, sharing, adaptation, distribution and reproduction in any medium or format, as long as you give appropriate credit to the original author(s) and the source, provide a link to the Creative Commons licence, and indicate if changes were made. The images or other third party material in this article are included in the article's Creative Commons licence, unless indicated otherwise in a credit line to the material. If material is not included in the article's Creative Commons licence and your intended use is not permitted by statutory regulation or exceeds the permitted use, you will need to obtain permission directly from the copyright holder. To view a copy of this licence, visit http://creativecommons.org/licenses/by/4.0/. The Creative Commons Public Domain Dedication waiver (http://creativecommons.org/publicdomain/zero/1.0/) applies to the data made available in this article, unless otherwise stated in a credit line to the data. 


\section{Background}

In patients with chronic kidney disease (CKD) cardiovascular complications are the main cause of mortality [1, $2]$. These cardiovascular complications are often a consequence of vascular calcification, which occurs in $80 \%$ of CKD patients with end-stage disease [3]. Vascular calcification is provoked by disturbances in mineral-bone metabolism in CKD, mainly characterized by hyperphosphatemia [4]. Currently, there is no effective treatment for vascular calcification. Presently used methods aimed at lowering blood phosphate $(\mathrm{Pi})$ concentrations are insufficient to limit vascular calcification or cardiovascular disease risk [5]. Over the past decade, magnesium $\left(\mathrm{Mg}^{2+}\right)$ has gained attention as a potential modifiable risk factor of vascular calcification in CKD [6]. Indeed, recent data demonstrate that magnesium prevents the formation of secondary calciprotein particles, which contribute to the development of medial calcification. Phosphate is the major determinant of secondary calciprotein particle formation and explains why CKD patients are prone to the development of these particles. Magnesium is a protective factor in the calcification milieu, which may act as a phosphate-buffering system to prevent secondary calciprotein particle development [7].

Increased plasma $\mathrm{Mg}^{2+}$ is associated with reduced risk for all-cause and cardiovascular mortality in the general population and in CKD patients [8-15]. More specifically, $\mathrm{Mg}^{2+}$ effectively prevents vascular calcification in human vascular smooth muscle cells as well as in a variety of rodents [16-18]. A recent clinical trial in CKD patients reported immediate effects of increasing both oral and dialysate $\mathrm{Mg}^{2+}$ on calcification propensity of human serum, as measured by in-vitro analysis [19-21]. Combined, these studies demonstrate that increasing plasma $\mathrm{Mg}^{2+}$ concentrations reduces vascular calcification risk and progression in end-stage CKD patients. Until now, most observational cohort studies on which clinical trials are based have focused on the association between $\mathrm{Mg}^{2+}$ and vascular calcification in hemodialysis patients. However, the potential importance of plasma $\mathrm{Mg}^{2+}$ concentration for vascular calcification in earlier stages of CKD remains underexplored.

The aim of this study was to investigate whether plasma $\mathrm{Mg}^{2+}$ is a determinant for the presence and severity of vascular calcification in moderate CKD. We performed a retrospective study using abdominal aortic calcification (AAC) scores in patients with stage 3 and 4 CKD that were enrolled in the MASTERPLAN (Multifactorial Approach and Superior Treatment Efficacy in Renal Patients with the Aid of Nurse practitioners) trial [22].

\section{Methods}

\section{Design and patient inclusion}

A comprehensive description of patient selection and the assessment of AAC has been previously reported by
Peeters et al. [23] For the reader's convenience we will briefly summarize the approach. The MASTERPLAN (Multifactorial Approach and Superior Treatment Efficacy in Renal Patients with the Aid of Nurse practitioners) study was a randomized controlled trial that started inclusion in 2004 (ISRCTN73187232). Rationale, design and outcomes are reported elsewhere [22, 24, 25]. In summary, the MASTERPLAN trial was designed as a multifactorial intervention comparing additional renal nurse support to standard care to reduce cardiovascular and renal risk in patients with moderate CKD. Adult patients with moderate to severe CKD (estimated creatinine clearance between 20 and $70 \mathrm{ml} / \mathrm{min} / 1.73 \mathrm{~m}^{2}$ ) were included [22]. Patients with a renal transplant $<1$ year before screening, acute kidney injury or rapidly progressing glomerular nephritis, any malignancy $<5$ years before screening (other than basocellular or squamous cell carcinoma of the skin) or participating in other clinical trials that required the use of study medication were excluded from the study [22]. The study was performed in accordance with the declaration of Helsinki. All patients provided written informed consent, and medical ethical approval was obtained prior to initiation of the MASTERPLAN trial. In the period of 2008-2009 nephrologists considered to role of evaluating AAC in selected patients, based on the data and discussions that resulted in the recommendation in the 2009 KDIGO CKD-MBD guideline $[23,26]$. As the $\mathrm{X}$-ray was not in the initial trial protocol, the decision to take X-rays was left to the treating nephrologist. In total 280 patients had an X-ray. The lateral abdominal X-rays were reviewed by two independent reviewers.

\section{Assessment of abdominal aortic calcification}

The presence of AAC was determined and scored according to the method described by Kauppila et al. [27] This calcification score takes into account the anterior and the posterior arterial all separately, and ranges from 0 to 24. A detailed description of the calcification grading in the MASTERPLAN study has been documented previously [23]. The interrater agreement was excellent with a linear weighted kappa of 0.87 . In only 8 of the 2240 rated aorta segments the score deviated $>1$ point.

\section{Plasma magnesium measurements}

Plasma $\mathrm{Mg}^{2+}$ concentrations were determined for all patients in $\mathrm{mmol} / \mathrm{L}$ using a colorimetric assay according to the manufacturer's protocol (Roche, Basel, Switzerland) and measured at $600 \mathrm{~nm}$ on a Bio-Rad Benchmark plus microplate reader (Bio-Rad Laboratories, Hercules, California, USA). Plasma samples had been frozen and stored at $-80^{\circ}$ prior to analysis. All measurements were performed in triplicate. Plasma $\mathrm{Mg}^{2+}$ concentrations 
were measured at baseline, after one year and at the time of the X-ray (after four years).

\section{Statistical analyses}

Baseline data were described by frequencies and proportion for categorical variables, mean and standard deviation (SD) for normally distributed continuous variables, and median and interquartile range for continuous variables with a skewed distribution. We investigated the dose response relation between AAC score and serum $\mathrm{Mg}^{2+}$ by creating a scatterplot and fitting a LOESS smoothed regression line. As the association between AAC and plasma $\mathrm{Mg}^{2+}$ was approximately linear, no transformations were considered. Next, we reviewed missing data patterns (Supplementary Table S1) and used multiple imputation with chained equations to impute missing values using R-package 'mice' [28]. Predictive mean matching was used to impute missing values for continuously distributed variables and logistic regression was used to impute missing values for dichotomous variables. For all imputation models, predictors with a bivariate correlation of $>0.15$ were considered. Diagnostic plots indicated that the imputations were stable over five iterations. Strip plots showed that imputed values all fell within the range of the observed values and were distributed across the entire range of observed values (Supplementary Figure S1).

In order to obtain a valid estimate for the association between plasma $\mathrm{Mg}^{2+}$ and AAC a multivariate model that adjusts for important confounders is required. To identify the variables that should be adjusted for, a causal model with the hypothesized relation between plasma $\mathrm{Mg}^{2+}$ and AAC was created. A directed acyclic graph was created with dagitty.net software and associated R-package to encode model assumptions [29]. Implied conditional independencies stemming from the model were tested and the model was refined until no gross violations were detected (see Supplementary Table S2 for the results of the conditional independency tests and Supplementary Fig. S2 for the final causal model). We arrived at two possible adjustment sets (Table 2). Both were used to obtain an adjusted estimate for the association between plasma $\mathrm{Mg}^{2+}$ concentration and AAC.

As 79 of the 280 patients had no calcifications we used a zero-inflated Poisson model to determine the association between plasma $\mathrm{Mg}^{2+}$ concentration and AAC. The model assumes that the zeros are generated by another process than the count data, and therefore that these processes can be modeled separately. The model consists of two parts. First, a Poisson model for the continuous data with values $>0$, and second a logistic model that estimates the log-odds of a zero observation. Additionally, we included an off-set for the time between
$\mathrm{Mg}^{2+}$ measurement and the $\mathrm{X}$-ray in the Poisson submodel.

All analyses were performed with RStudio (version 1.1.463 - () 2009-2018 RStudio, Inc.), R (version 3.5.3 for Windows) and the following packages: dagitty_0.2-3, boot_1.3-20, mice_3.5.0, V8_2.2, car_3.0-2, survival_ 2.44-1.1, tableone_0.10.0, ggplot2_3.1.0, dplyr_0.8.1, foreign_0.8-71 (Item S1) [30].

\section{Results}

\section{Patient population}

Table 1 shows the baseline characteristics of the 280 patients included in the analysis [23]. This cohort consisted of relatively young patients with a mean age of 61 years. With an average eGFR of $41 \mathrm{ml} / \mathrm{min} / 1.73 \mathrm{~m}^{2}$ patients had moderately to severely decreased renal function. In total, 79 out of 280 patients did not have AAC (AAC = 0 ) and the median calcification score was 3.5 (interquartile range: $0.0-8.6$ ) [21]. The majority of the included patients was diagnosed with a hypertensive or renovascular cause of CKD. Only $10 \%$ of the patients had diabetic nephropathy as cause of the CKD, while $23 \%$ of the patients had diabetes. Around $30 \%$ of the patients had cardiovascular disease at time of inclusion. In addition, $\mathrm{Pi}$ and fibroblast growth factor 23 (FGF-23) concentrations fell within the normal range and did not differ between patients with or without AAC.

\section{Distribution of plasma magnesium concentrations}

For all 280 patients, plasma $\mathrm{Mg}^{2+}$ concentration was measured at baseline, after one year and after four years. After a median period of 3.7 (interquartile range: 3.14.0) years after baseline, the X-rays were performed [21]. The mean plasma $\mathrm{Mg}^{2+}$ concentration was $0.76 \pm 0.10$ $\mathrm{mmol} / \mathrm{L}$ at baseline (Fig. 1A). Patients without AAC appeared to have somewhat higher plasma $\mathrm{Mg}^{2+}$ concentrations at baseline (Fig. 1B). No marked differences in plasma $\mathrm{Mg}^{2+}$ concentrations were observed between baseline, after one year $(0.76 \pm 0.10 \mathrm{mmol} / \mathrm{L})$ and at time of X-ray $(0.74 \pm 0.10 \mathrm{mmol} / \mathrm{L})$. The lowest and the highest $\mathrm{Mg}^{2+}$ concentration were measured at 0.35 and 1.05 $\mathrm{mmol} / \mathrm{L}$, respectively. Approximately $16 \%$ of the patients had hypomagnesaemia with a plasma $\mathrm{Mg}^{2+}$ concentration below $0.7 \mathrm{mmol} / \mathrm{L}$.

\section{Dose-response relation between magnesium and AAC}

The dose-response relationship between plasma $\mathrm{Mg}^{2+}$ concentration and the AAC score determined from X-rays taken three to four years later is shown in Fig. 2. The crude Poisson model demonstrated that a $0.1 \mathrm{mmol} / \mathrm{L}$ higher plasma $\mathrm{Mg}^{2+}$ concentration was associated with a 0.07 point lower value of AAC ( $95 \%$ Confidence Interval (CI) $-0.28-0.014)$. The crude logistic model showed that a $0.1 \mathrm{mmol} / \mathrm{L}$ higher baseline plasma $\mathrm{Mg}^{2+}$ concentration 
Table 1 Baseline characteristics

\begin{tabular}{|c|c|c|c|c|}
\hline & Total & No AAC & AAC & $P$ \\
\hline $\bar{n}$ & 280 & 79 & 201 & \\
\hline Randomized to intervention group & $164(58.6)$ & $46(58.2)$ & $118(58.7)$ & 1.00 \\
\hline Female gender & $88(31.4)$ & $28(35.6)$ & $60(29.9)$ & 0.45 \\
\hline Age (years) & $61.0[51.7,68.0]$ & $49.0[39.5,60.0]$ & $64.0[57.0,70.0]$ & $<0.001$ \\
\hline \multicolumn{5}{|l|}{ Race } \\
\hline Caucasian & $251(89.6)$ & $68(86.1)$ & $183(91.0)$ & \\
\hline Non-Caucasian & $29(10.4)$ & $11(13.9)$ & $18(9.0)$ & \\
\hline Diagnosis $^{a}$ & & & & 0.04 \\
\hline Diabetic Nephropathy & $30(10.7)$ & $5(6.3)$ & $25(12.4)$ & \\
\hline Renovascular & $87(31.1)$ & $17(21.5)$ & $70(34.8)$ & \\
\hline Glomerulonephritis & $53(18.9)$ & $20(25.3)$ & $33(16.4)$ & \\
\hline Interstitial Nephritis & $30(10.7)$ & $13(16.5)$ & $17(8.5)$ & \\
\hline Congenital & $25(8.9)$ & $9(11.4)$ & $16(8.0)$ & \\
\hline Unknown & $55(19.6)$ & $15(19.0)$ & $40(19.9)$ & \\
\hline Diabetes $^{\mathrm{b}}$ & $64(22.9)$ & $9(11.4)$ & $55(27.4)$ & 0.01 \\
\hline $\mathrm{CVD}^{c}$ & $81(28.9)$ & $10(12.7)$ & $71(35.3)$ & $<0.001$ \\
\hline Current smoker & $52(18.6)$ & $13(16.5)$ & $39(19.5)$ & 0.68 \\
\hline BMI $\left(\mathrm{kg} / \mathrm{m}^{2}\right)$ & $26.0[23.6,28.0]$ & $24.6[23.1,26.5]$ & $26.5[24.2,28.4]$ & $<0.001$ \\
\hline Waist hip ratio & $0.95(0.08)$ & $0.94(0.08)$ & $0.96(0.08)$ & 0.04 \\
\hline $\mathrm{SBP}(\mathrm{mmHg})$ & $133(20)$ & $128(17)$ & $135(21)$ & 0.01 \\
\hline $\mathrm{DBP}(\mathrm{mmHg})$ & $77(11)$ & $78(10)$ & $77(12)$ & 0.21 \\
\hline $\mathrm{eGFR}\left(\mathrm{mL} / \mathrm{min}\right.$ per $\left.1.73 \mathrm{~m}^{2}\right)$ & $41.8(19.0)$ & $43.1(20.2)$ & $41.3(18.5)$ & 0.48 \\
\hline Serum creatinine $(\mu \mathrm{mol} / \mathrm{L})$ & $161.3[129.9,198.8]$ & $163.8[133.4,195.3]$ & $160.8[127.9,201.8]$ & 0.72 \\
\hline Serum albumin ( $g / d L)$ & $40.5(3.7)$ & $41.0(4.0)$ & $40.3(3.5)$ & 0.15 \\
\hline Total serum cholesterol (mmol/L) & $4.89(1.08)$ & $4.99(1.15)$ & $4.85(1.05)$ & 0.33 \\
\hline LDL cholesterol (mmol/L) & $2.83(0.98)$ & $2.87(1.09)$ & $2.81(0.94)$ & 0.64 \\
\hline Hemoglobin (mmol/L) & $8.3(0.9)$ & $8.2(1.0)$ & $8.4(0.9)$ & 0.09 \\
\hline $\mathrm{Ca}^{2+}(\mathrm{mmol} / \mathrm{L})$ & $2.38(0.14)$ & $2.39(0.16)$ & $2.37(0.13)$ & 0.23 \\
\hline $\mathrm{Mg}^{2+}(\mathrm{mmol} / \mathrm{L})$ & $0.76(0.10)$ & $0.73(0.10)$ & $0.77(0.09)$ & 0.01 \\
\hline $\mathrm{Pi}(\mathrm{mmol} / \mathrm{L})$ & $1.07[0.94,1.21]$ & $1.07[0.92,1.18]$ & $1.08[0.94,1.24]$ & 0.20 \\
\hline FGF-23 (RU/L) & $100.3[58.8,166.7]$ & $91.1[51.4,161.2]$ & $108.0[64.0,168.0]$ & 0.18 \\
\hline PTH (pmol/L) & $8.1[5.2,12.6]$ & $8.3[5.4,14.1]$ & $8.0[5.2,12.1]$ & 0.52 \\
\hline hsCRP (mg/dL) & $2.0[0.8,51.3]$ & $1.7[0.6,4.3]$ & $2.1[1.0,5.6]$ & 0.09 \\
\hline Proteinuria (g/24 h) & $0.2[0.1,0.6]$ & $0.2[0.1,0.6]$ & $0.2[0.1,0.6]$ & 0.28 \\
\hline ACEi/ARB use & $239(85.4)$ & $62(78.5)$ & $177(88.1)$ & 0.06 \\
\hline Diuretic use & $137(48.9)$ & $31(39.2)$ & $106(52.7)$ & 0.06 \\
\hline Other antihypertensives & $157(56.1)$ & $34(43.0)$ & $123(61.2)$ & 0.01 \\
\hline Lipid lowering drugs & $204(72.9)$ & $46(58.2)$ & $158(78.6)$ & 0.001 \\
\hline Vitamin D use & $49(17.5)$ & $16(20.3)$ & $33(16.4)$ & 0.56 \\
\hline Phosphate binder use & $25(8.9)$ & $8(10.1)$ & $17(8.5)$ & 0.84 \\
\hline AAC score & $3.50[0.00,8.62]$ & $0.00[0.00,0.00]$ & $6.50[3.00,10.50]$ & \\
\hline
\end{tabular}

Studied by logistic regression. Data are given as number (\%), mean (SD) or median [interquartile range]

$A A C$ Abdominal aortic calcification, $A C E i$ Angiotensin converting enzyme inhibitor, $A R B$ Angiotensin-II receptor blockers, $B M I$ Body mass index, $C a^{2+}$ Calcium (conversion factor $/ 0.2495$ for $\mathrm{mg} / \mathrm{dL}$ ), CVD Cardiovascular disease, DPB Diastolic blood pressure, eGFR Estimated glomerular filtration rate, FGF-23 Fibroblast growth factor 23, hsCRP High-sensitivity C-reactive protein, LDL Low-density lipoprotein (conversion factor cholesterol $/ 0.02586$ for $\mathrm{mg} / \mathrm{dL}$ ), $M g^{2+} \mathrm{Magnesium,} P i$ Phosphate (conversion factor $/ 0.3229$ for $\mathrm{mg} / \mathrm{dL}$ ), PTH Parathyroid hormone, SBP Systolic blood pressure. Creatinine conversion factor $/ 88.4$ for $\mathrm{mg} / \mathrm{dL}$

${ }^{a}$ Diagnosis of the underlying renal disease was determined by the treating physician using available patient history, clinical course and if available histopathology ${ }^{b}$ Diabetes was defined as using blood glucose lowering medication or fasting glucose $>7.0 \mathrm{mmol} / \mathrm{L}$

${ }^{c}$ Cardiovascular disease was defined as myocardial infarction, stroke or vascular intervention

dUsing the MDRD (modification of diet in renal disease) eq. (186 x (Creatinine/88.4) ${ }^{-1.154} \times(\text { Age })^{-0.203} \times(0.742$ if female) $\times(1.210$ if black), re-expressed for standardized serum creatinine 

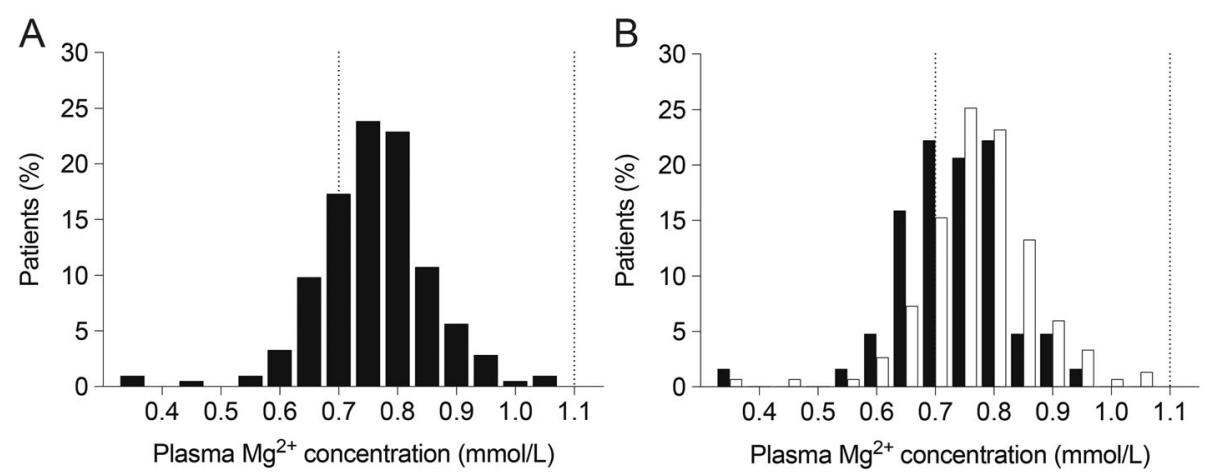

Fig. 1 Plasma $\mathrm{Mg}^{2+}$ concentrations in non-dialysis CKD patients. Distribution of $\mathrm{Mg}^{2+}$ concentrations (A). Plasma $\mathrm{Mg}^{2+}$ concentrations for CKD patients with (indicated in white) and without (indicated in black) abdominal aortic calcifications (B). Dotted vertical lines indicate the reference values for $\mathrm{Mg}^{2+}$ concentration $(0.7-1.1 \mathrm{mmol} / \mathrm{L})$

resulted in $30 \%$ lower odds for detecting any AAC three to four years later $(\mathrm{OR}=0.63 ; 95 \%$ CI 0.29 to 1.37). The association between AAC at year three or four and $\mathrm{Mg}$ measurement at year one $\mathrm{n}$ was attenuated compared to baseline to $7 \%$ per $0.1 \mathrm{mmol} / \mathrm{L}$ increase in plasma $\mathrm{Mg}^{2+}(\mathrm{OR}=0.93 ; 95 \%$ CI $0.61-1.43)$. Likewise, when $\mathrm{Mg}^{2+}$ measurements were taken at the same time as the X-ray the odds of absence of a calcification were $7 \%$ per $0.1 \mathrm{mmol} / \mathrm{L} \mathrm{Mg}^{2+}$ increase $(\mathrm{OR}=0.93 ; 95 \%$ CI $0.60-1.45)$. Adjustment did not substantially change this association (Table 2). None on the association described above reached statistical significance, as can be determined from the $95 \%$ confidence intervals overlapping 1.0.

\section{Discussion}

In this study, we aimed to investigate whether plasma $\mathrm{Mg}^{2+}$ concentration is a determinant for the presence and severity of vascular calcification in moderate CKD. We have identified a modest, not statistically significant association between AAC score and plasma $\mathrm{Mg}^{2+}$ concentration. For every higher value of $0.1 \mathrm{mmol} / \mathrm{L}$ plasma $\mathrm{Mg}^{2+}$ the associated AAC score is lower by approximately 0.1 point. In addition, a more pronounced association was present between higher plasma $\mathrm{Mg}^{2+}$ concentration at baseline and the absence of AAC four years later. Specifically, the odds of finding any AAC on the X-ray after four years are $30 \%$ lower per $0.1 \mathrm{mmol} / \mathrm{L}$ higher value in plasma $\mathrm{Mg}^{2+}$ concentration at baseline. The observed association weakens markedly after one year (shorter period before the X-ray) and is almost absent when plasma $\mathrm{Mg}^{2+}$ concentration is measured at time of the X-ray.

Other studies have reported stronger associations between plasma or serum $\mathrm{Mg}^{2+}$ concentration and calcification score [9, 10, 31-35]. Molnar et al. showed that a $0.1 \mathrm{mmol} / \mathrm{L}$ higher serum $\mathrm{Mg}^{2+}$ concentration was associated with a 1.1-point lower AAC score in end-stage renal disease patients [34]. In pre-dialysis CKD patients, every $\mathrm{mg} / \mathrm{dL}(0.4 \mathrm{mmol} / \mathrm{L})$ higher serum $\mathrm{Mg}^{2+}$ concentration was associated with a 0.36 point lower CACdensity score (scale 1-3.5) [33]. Interestingly, Sakaguchi et al. described that the association between $\mathrm{Mg}^{2+}$ and $\mathrm{AAC}$ in pre-dialysis patients is dependent on serum $\mathrm{Pi}$ concentration. This association was only identified in a sub-group where serum Pi concentration was above 1.1 $\mathrm{mmol} / \mathrm{L}$, but not in patients with a $\mathrm{Pi}$ concentration below $1.1 \mathrm{mmol} / \mathrm{L}$. [33] In the MASTERPLAN cohort, median plasma Pi concentration was $1.07 \mathrm{mmol} / \mathrm{L}$. In other studies describing an association between $\mathrm{Mg}^{2+}$ concentration and AAC, the mean serum Pi concentration exceeded $1.49 \mathrm{mmol} / \mathrm{L}$ (Table 3 ). The relatively low Pi concentration potentially related to CKD stage may explain the weak correlation between $\mathrm{Mg}^{2+}$ concentration and AAC score found in our study. Of note, with a plasma $\mathrm{Mg}^{2+}$ concentration of $0.76 \pm 0.10 \mathrm{mmol} / \mathrm{L}$, plasma $\mathrm{Mg}^{2+}$ concentrations were low in comparison to other studies (Table 3). These relatively low $\mathrm{Mg}^{2+}$ concentrations, in addition to the low variation, could be a reason for the absence of a stronger relationship between plasma $\mathrm{Mg}^{2+}$ concentration and AAC score. Moreover, the average $\mathrm{Mg}^{2+}$ concentrations at baseline was higher in the AAC group. However, in the inferential analysis we accounted for other possible determinants of AAC. These include diabetes, higher age, prior cardiovascular and serum calcium and phosphate. Diabetes prevalence, age, and CVD prevalence were substantially higher in the AAC group, while serum calcium and phosphate concentrations were similar. The crude association between $\mathrm{Mg}^{2+}$ and $\mathrm{AAC}$ in our study, may thus be explained by these confounding factors However, absence of evidence does not mean evidence of absence. We hypothesize that the absence of a relation in our cohort may have two reasons: First the serum $\mathrm{Mg}^{2+}$ concentrations were fairly low, possibly insufficient to achieve and effect on AAC. Second, $\mathrm{Mg}^{2+}$ may not have 


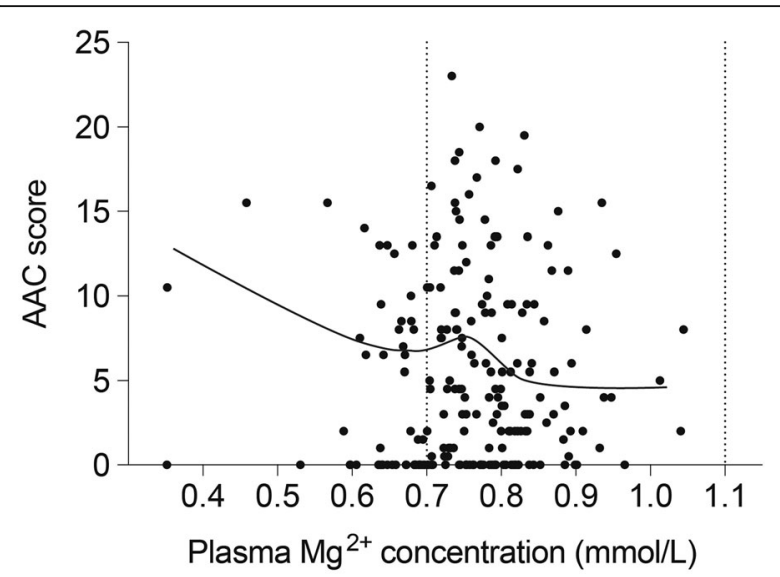

Fig. 2 Dose-response relation between $\mathrm{Mg}^{2+}$ and abdominal aortic calcification score. The abdominal aortic calcification (AAC)-score for each patient are presented individually and plotted against their plasma $\mathrm{Mg}^{2+}$ concentration at baseline. Dose-response relation between AAC and plasma $\mathrm{Mg}^{2+}$ concentration was investigated by creating a scatter plot and fitting a LOESS smoothed regression line. No transformations were considered due to linearity of the association. Dotted vertical lines indicate the reference values for $\mathrm{Mg}^{2+}$ concentration $(0.7-1.1 \mathrm{mmol} / \mathrm{L})$

a (clinically meaningful) effect on established AAC. By design we could ascertain if patients had AAC at baseline already. Of note, the plasma $\mathrm{Mg}^{2+}$ concentrations for each patient were stable between the measurements. In advanced CKD, serum $\mathrm{Mg}^{2+}$ concentrations tend to increase, reaching values of around $0.97 \mathrm{mmol} / \mathrm{L}$. [13] In addition, the median AAC score in this study was 3.5, while in stage 5 CKD mean AAC was 8.9 (scale 0-24) [34]. Our study population included patients with moderate CKD, with most in stage $3 \mathrm{~b}$. It is possible that a more pronounced association between $\mathrm{Mg}^{2+}$ concentration and AAC is present in more advanced stages of CKD.

Our results suggest that a $0.1 \mathrm{mmol} / \mathrm{L}$ higher value of plasma $\mathrm{Mg}^{2+}$ concentration is associated with $30 \%$ reduced risk of having any AAC, although not statistically significantly. Because vascular calcification is irreversible once established, determining the optimal window of effective treatment, potentially using $\mathrm{Mg}^{2+}$, is essential [40]. To date, most epidemiological studies have investigated whether plasma $\mathrm{Mg}^{2+}$ concentration is associated with vascular calcification in dialysis patients where calcification has already progressed (Table 3) [9, 31, 32, 34, 37]. Vascular calcification often manifests already in earlier stages of CKD. Our results indicate that, at least in this cohort consisting of 280 non-dialysis CKD patients, the effects of $\mathrm{Mg}^{2+}$ may be lagged. Therefore, supplementation of $\mathrm{Mg}^{2+}$ may be less effective once AAC has already formed. This notion is in line with the study of Bressendorff et al, showing that an increase in blood $\mathrm{Mg}^{2+}$ concentration of $0.34 \mathrm{mmol} / \mathrm{L}$ results in reduced calcification propensity, which reflects a lower $\mathrm{Ca}^{2+}$-Pi precipitation risk [19]. The calcification propensity test determines the formation of calcium phosphate particles in human serum in an in vitro setup. Thus, the study of Bressendorff determines the ex vivo formation of calcium precipitates, rather than measuring already formed calcification. As such, the study supports our data and demonstrates that magnesium may prevent the formation of calcification, but will not affect calcification already in place.

A vast body of observational studies has identified associations between the blood $\mathrm{Mg}^{2+}$ concentration and cardiovascular and all-cause mortality in end-stage renal disease patients $[6,11,13]$. While subsequent in vitro and animal study evidence has been compelling, clinical studies assessing the effectiveness of $\mathrm{Mg}^{2+}$ in preventing vascular calcification have been scarce [16-18, 41-43]. Recently, in a randomized clinical study oral $\mathrm{Mg}^{2+}$ supplementation resulted in diminished progression of coronary artery calcification (CAC)-score in pre-dialysis CKD patients [44]. While more clinical studies are currently underway, it is of importance to evaluate the most effective window of intervention, which is likely in early CKD before onset of vascular calcification.

Strengths of our study include the use of a well characterized study cohort that has been followed-up according to standardized procedures and with extensive biobanking. In addition, we used the state-of-the-art methodology for causal inference to create an explicit and testable causal model. Furthermore, plasma $\mathrm{Mg}^{2+}$ concentrations were obtained at several time points which allowed for the determination of the latency of the protective effect of plasma $\mathrm{Mg}^{2+}$ concentration on vascular calcification. The calcifications were scored with high interrater reliability, reducing the possibility of misclassification.

A major limitation of our study was the relatively small sample size and the fact that a lumbar X-ray was only available in a subgroup of patients. A selection bias may have been created by selecting patients that received the X-ray that were relatively healthy. Although the differences were small, patients that received the $\mathrm{X}$ ray had a lower renal risk and a higher cardiovascular risk profile. Moreover, patients in the MASTERPLAN trial were fairly well controlled both at baseline and follow-up. Therefore, this population may not be completely representative of the average CKD population. Furthermore, some variables had missing values, mostly during follow-up. Missingness was handled by using multiple imputation. However, while this approach reduces the likelihood of selection bias, it does introduce noise in the covariate values. As a consequence, residual confounding may remain despite statistical adjustment. Furthermore, as already discussed for the MASTERPLAN cohort study in a previous publication, the 
Table 2 Associations between AAC and plasma $\mathrm{Mg}^{2+}$ in multivariate analysis

\section{AAC incidence}

Univariate analysis

Baseline

$$
\text { Count (Poisson model) }
$$

Odds Ratio (zero model)

1 year

Count (Poisson model)

Odds Ratio (zero model)

$X$ ray

Count (Poisson model)

Odds Ratio (zero model)

Adjusted for age, calcium, phosphate, cardiovascular disease, and diabetes

Baseline

Count (Poisson model)

Odds Ratio (zero model)

1 year

Count (Poisson model)

Odds Ratio (zero model)

$X$ ray

Count (Poisson model)

Odds Ratio (zero model)
$95 \% \mathrm{Cl}$

$-0.28-0.14$

$0.29-1.37$

$-0.51-0.35$

$0.61-1.43$

$-0.51-0.35$

$0.60-1.45$

$-0.58-0.44$

$0.29-1.37$

$-0.51-0.35$

$0.61-1.43$

$-0.51-0.35$

$0.60-1.45$

Adjusted for age, calcium, phosphate, cardiovascular disease, eGFR, and PTH

Baseline

Count (Poisson model)

Odds Ratio (zero model)

1 year

Count (Poisson model)

Odds Ratio (zero model)

0.94

Count (Poisson model)

Odds Ratio (zero model)

Adjusted for age, eGFR, phosphate, and diuretics

Baseline

Count (Poisson model)

$-0.08$

Odds Ratio (zero model)

1 year

Count (Poisson model)

Odds Ratio (zero model)

$X$ ray

Count (Poisson model)

0.94
$-0.53-0.39$

$0.32-1.30$

$-0.45-0.32$

$0.63-1.38$

$-0.44-0.31$

$0.63-1.38$

$-0.53-0.38$

$0.34-1.23$

$-0.48-0.35$

$0.61-1.41$

$-0.48-0.33$

$0.63-1.40$

A zero-inflated Poisson model was used to determine the association between plasma $\mathrm{Mg}^{2+}$ concentration and AAC. The model assumes that the zeros are generated by another process than the count data, and therefore that these processes can be modeled separately. The model consists of two parts. First, a Poisson model for the continuous data with values $>0$ and second, a logistic model that estimates the Log-odds of a zero observation Results are presented per $0.1 \mathrm{mmol} / \mathrm{L}$ increase in plasma $\mathrm{Mg}^{2+}$

$\mathrm{Ca}^{2+}$ Calcium, $\mathrm{Cl}$ Confidence interval, $\mathrm{Mg}^{2+}$ Magnesium 
Table 3 Overview of studies assessing the relationship between blood $\mathrm{Mg}^{2+}$ concentration and vascular calcification

\begin{tabular}{|c|c|c|c|c|c|c|c|c|c|}
\hline Reference $^{\#}$ & Study type & $\begin{array}{l}\text { CKD } \\
\text { stage }\end{array}$ & $\begin{array}{l}\text { Sample } \\
\text { size (\% } \\
\text { women) }\end{array}$ & $\begin{array}{l}\mathrm{Mg}^{2+} \\
\text { concentration }\end{array}$ & $\begin{array}{l}\mathrm{Pi} \\
\text { concentration }\end{array}$ & Type & $\begin{array}{l}\text { Follow- } \\
\text { up } \\
\text { (years) }\end{array}$ & $\begin{array}{l}\text { Association } \\
(P<0.05)\end{array}$ & $\begin{array}{l}\text { Associations serum } \mathrm{Mg}^{2+} \\
\text { concentration }(\mathrm{mmol} / \mathrm{L})\end{array}$ \\
\hline $\begin{array}{l}\text { Meema et } \\
\text { al. } 1987 \text { [9] }\end{array}$ & Prospective & 5 & $44(0)$ & 1.16 & 1.88 & $\begin{array}{l}\text { Peripheral } \\
\text { AC }\end{array}$ & 2 & Yes & $\begin{array}{l}1.10 \pm 0.21 \text { in } A C \text { compared } \\
\text { to } 1.24 \pm 0.21 \text { in non-AC }\end{array}$ \\
\hline $\begin{array}{l}\text { Tzanakis et } \\
\text { al. } 1997 \\
{[36]}\end{array}$ & $\begin{array}{l}\text { Cross- } \\
\text { sectional }\end{array}$ & 5 & $56(39)$ & 1.23 & 1.63 & MAC & - & Yes & $\begin{array}{l}1.14 \pm 0.12 \text { in MAC versus } \\
1.27 \pm 0.10 \text { in non-MAC }\end{array}$ \\
\hline $\begin{array}{l}\text { Ishimura et } \\
\text { al. } 2007 \\
{[37]}\end{array}$ & $\begin{array}{l}\text { Cross- } \\
\text { sectional }\end{array}$ & 5 & $390(42)$ & 1.14 & 1.87 & AC (hand) & - & Yes & $\begin{array}{l}1.10 \pm 0.12 \text { in } V C \text { versus } \\
1.14 \pm 0.14 \text { in non-VC }\end{array}$ \\
\hline $\begin{array}{l}\text { Matias et } \\
\text { al. 2014 } \\
{[32]}\end{array}$ & Prospective & 5 & $206(45)$ & 1.36 & 1.49 & SVCS & 4 & Yes & $\begin{array}{l}\beta \text {-coefficient } 0.1795 \% \mathrm{Cl} \\
0.08-0.30 \text { (cut-off } \\
\text { concentration 1.15) }\end{array}$ \\
\hline $\begin{array}{l}\text { Sakaguchi } \\
\text { et al. } 2016 \\
\text { [33] }\end{array}$ & $\begin{array}{l}\text { Cross- } \\
\text { sectional }\end{array}$ & $3-4$ & $109(33)$ & 0.85 & $\geq 1.10$ & CAC & - & Yes & $\begin{array}{l}\beta \text {-coefficient }-0.36(\mathrm{Cl} \text { not } \\
\text { reported })^{2}\end{array}$ \\
\hline $\begin{array}{l}\text { Molnar et } \\
\text { al. } 2017 \\
\text { [34] }\end{array}$ & $\begin{array}{l}\text { Cross- } \\
\text { sectional }\end{array}$ & 5 & $80(30)$ & 0.84 & 1.70 & AAC & - & Yes & $\begin{array}{l}\text { Adjusted } R^{2} 0.18, \beta- \\
\text { coefficient }-12.27,95 \% \mathrm{Cl}- \\
19.54--5.00^{3}\end{array}$ \\
\hline $\begin{array}{l}\text { Okamoto } \\
\text { et al. } 2018 \\
\text { [35] }\end{array}$ & Retrospective & 5 & $128(36)$ & 0.90 & 1.74 & AAC & 1 & Yes & $\begin{array}{l}\text { OR 3.11, 95\% Cl 1.43-5.89 } \\
\text { (baseline serum } \mathrm{Mg}^{2+}<0.9 \text { ) }\end{array}$ \\
\hline $\begin{array}{l}\text { Tamura et } \\
\text { al. } 2019 \\
\text { [38] }\end{array}$ & Prospective & 5 & $392(34.7)$ & 1.15 & 1.65 & $A \circ A C$ & 4.2 & No & - \\
\hline
\end{tabular}

*(A/C)AC, (abdominal/coronary) arterial calcification; AoAc, aortic arch calcification; MAC, mitral annular calcifications; OR, odds ratio; SVCS, simple vascular calcification score (hands/pelvis); VC, vascular calcification

"Articles were obtained after PubMed search in October 2019 using the following search terms: ("Renal insufficiency, Chronic"[Mesh] OR "Chronic kidney disease"[TiAb]) AND "Magnesium"[Mesh/TiAb]) AND ("calcinosis"[mesh] OR "calcification"[TiAb])

${ }^{1}$ Scale of calcification score reported was not quantitative [39]. Score is based on presence in pre-determined locations and scores are made up out of the sum of positive locations, ranging from 0 to 8 [36]

${ }^{2} \mathrm{~S}$ cale of calcification density was reported between 0.86-3.33 (Agatston score divided by the total calcified area for each patient)

${ }^{3}$ Scale of calcification score (AAC) was reported 0-24

sensitivity of AAC measurements by lumbar X-ray is less compared to computed tomography measurements, leading to a potential underestimation of AAC severity [22, 23]. This could lead to misclassification of patients without AAC. Another limitation is the lack of X-ray data at baseline of the study, thus possible effects of $\mathrm{Mg}^{2+}$ on the rate of calcification in patients with established calcifications could not be investigated. Finally, we did not have information about the types of phosphate binding medication that patients used. Some of these may include magnesium salts..

\section{Conclusions}

In conclusion, a statistically nonsignificant association between $\mathrm{Mg}^{2+}$ and AAC in this study suggests a limited if any potential preventive effect $\mathrm{Mg}^{2+}$ on the development of AAC in non-dialysis CKD patients.

\section{Supplementary Information}

The online version contains supplementary material available at https://doi. org/10.1186/s12882-021-02267-4.

Additional file 1: Table S1. Missingness patterns at baseline. Table S2. Conditional independency tests for the causal assumption model. Figure S1. Diagnostic strip plots. Figure S2. Causal model for identification of adjustment sets. Item S1 Supplementary R-code.

\section{Abbreviations}

AAC: Abdominal aortic calcification; CAC: Coronary Artery Calcification; CKD: Chronic Kidney Disease; KDIGO CKD-MBD: Kidney Disease Improving Global Outcomes Chronic Kidney Disease - Mineral Bone Disease; MASTERPL AN: Multifactorial Approach and Superior Treatment Efficacy in Renal Patients with the Aid of Nurse practitioners trial; $\mathrm{Mg}^{2+}$ : Magnesium; LOESS: Locally estimated sum of squares; OR: Odds ratio; SD: Standard Deviation

\section{Acknowledgements}

We thank participating nephrologists Marjolijn van Buren, Karin A.H. Kaasjager, Yvo W.J. Sijpkens, Peter J.G. van de Ven, Gerald Vervoort, LouisJean Vleming and nurse practitioners Hanny Bergsma, Noeleen Berkhout, Paul Gundlach, Lidian Lensen, Simone Mooren, Kathy Schoenmakers, Ans Wieleman, Judith Wierdsma. We also thank Marc G. Vervloet for his valuable consulting. Furthermore, we thank Yelka Koster for reviewing and scoring the $\mathrm{X}$-rays. 


\section{Authors' contributions}

ADtB, JHFdB, JGJH and JAGJvdB conceived and designed the study. ADtB and LPG performed the $\mathrm{Mg}^{2+}$ measurements and JAGvdB performed statistical analysis of the data. ADtB, JHFdB and JAGJvdB interpreted the data. MJP, ADVZ, JFMW, PJBAll, JAGJvdB were involved in the original MASTERPL AN cohort study. ADtB and JAGJvdB wrote the manuscript. All authors have critically reviewed the manuscript. The author(s) read and approved the final manuscript.

\section{Funding}

This work was financially supported by grants from the Netherlands Organization for Scientific Research (NWO Veni 016.186.012 and VICI 016.130.668) and the Dutch Kidney Foundation (Kolff 14OKG17, 15OP02 and 16TKI02).

\section{Availability of data and materials}

Original study data and associated analysis scripts have been stored in a virtual environment on the anDREa platform (https://www.andreaconsortium.org/). Access can be requested via the corresponding author.

\section{Ethics approval and consent to participate}

All procedures performed in this study were in accordance with the ethical standards of the institutional research committees and with the 1964 Helsinki declaration and its later amendments or comparable ethical standards. The study was approved by Medical Ethics Committees of the participating centers, notably Canisius Wilhelmina Hospital, Nijmegen, Deventer Hospital, Deventer, Haga Hospital, The Hague, Leiden University Medical Center, Leiden, Medical Center Rijnmond Zuid, Rotterdam, Rijnstate Hospital, Arnhem, Radboud University Nijmegen Medical Center, Nijmegen, University Medical Center Utrecht, Utrecht.

Written informed consent was obtained from all individuals who participated in the MASTERPLAN study.

\section{Consent for publication}

No applicable.

\section{Competing interests}

The authors declare no conflict of interest.

\section{Author details}

'Department of Physiology, Radboud Institute for Molecular Life Sciences, Radboud University Medical Center, Nijmegen, The Netherlands.

${ }^{2}$ Department of Nephrology, Radboud Institute for Health Sciences, Radboud University Medical Center, PO box 9101, 6500, HB, Nijmegen, The Netherlands. ${ }^{3}$ Department of Nephrology, University Medical Center Utrecht, Utrecht, The Netherlands.

\section{Received: 8 November 2020 Accepted: 9 February 2021}

\section{Published online: 25 February 2021}

\section{References}

1. Mozaffarian D, Benjamin EJ, Go AS, et al. Heart disease and stroke statistics-2016 update. Circulation. 2016;133:447-54

2. Foley RN, Parfrey PS. Cardiovascular disease and mortality in ESRD. J Nephrol. 1998;11:239-45

3. Goodman WG, Goldin J, Kuizon BD, et al. Coronary-artery calcification in young adults with end-stage renal disease who are undergoing dialysis. N Engl J Med. 2000:342:1478-83.

4. Mathew S, Tustison KS, Sugatani T, Chaudhary LR, Rifas L, Hruska KA. The mechanism of phosphorus as a cardiovascular risk factor in CKD. J Am Soc Nephrol. 2008;19:1092-105.

5. Ruospo M, Palmer SC, Natale P, et al. Phosphate binders for preventing and treating chronic kidney disease-mineral and bone disorder (CKD-MBD). Cochrane Database Syst Rev. 2018;8(8):CD006023.

6. ter Braake AD, Shanahan CM, de Baaij JHF. Magnesium counteracts vascular calcification: passive interference or active modulation? Arterioscler Thromb Vasc Biol. 2017:37:1431-45.

7. Ter Braake AD, Vervloet MG, de Baaij JHF, Hoenderop JGJ. Magnesium to prevent kidney disease-associated vascular calcification: crystal clear? Nephrol Dial Transplant. 2020.
8. Gartside PS, Glueck CJ. The important role of modifiable dietary and behavioral characteristics in the causation and prevention of coronary heart disease hospitalization and mortality: the prospective NHANES I follow-up study. J Am Coll Nutr. 1995:14:71-9.

9. Meema HE, Oreopoulos DG, Rapoport A. Serum magnesium level and arterial calcification in end-stage renal disease. Kidney Int. 1987;32:388-94.

10. Ishimura E, Okuno S, Yamakawa T, Inaba M, Nishizawa Y. Serum magnesium concentration is a significant predictor of mortality in maintenance hemodialysis patients. Magnes Res. 2007;20:237-44.

11. Kanbay M, Yilmaz Ml, Apetrii M, et al. Relationship between serum magnesium levels and cardiovascular events in chronic kidney disease patients. Am J Nephrol. 2012;36:228-37.

12. Sakaguchi $Y$, Fujii N, Shoji T, Hayashi T, Rakugi H, Isaka Y. Hypomagnesemia is a significant predictor of cardiovascular and non-cardiovascular mortality in patients undergoing hemodialysis. Kidney Int. 2014;85:174-81.

13. de Roij van Zuijdewijn CLM, Grooteman MPC, Bots ML, et al. Serum magnesium and sudden death in European hemodialysis patients. PLoS One. 2015;10:e0143104.

14. Yu L, Li H, Serum Magnesium WS-X. Mortality in maintenance hemodialysis patients. Blood Purif. 2016:43:31-6.

15. Cai K, Luo Q, Dai Z, et al. Hypomagnesemia is associated with increased mortality among peritoneal dialysis patients. PLoS One. 2016;11:e0152488.

16. Louvet L, Büchel J, Steppan S, Passlick-Deetjen J, Massy ZA. Magnesium prevents phosphate-induced calcification in human aortic vascular smooth muscle cells. Nephrol Dial Transplant. 2013;28:869-78.

17. ter Braake AD, Tinnemans PT, Shanahan CM, Hoenderop JGJ, de Baaij JHF. Magnesium prevents vascular calcification in vitro by inhibition of hydroxyapatite crystal formation. Sci Rep. 2018;2069:1-11.

18. Diaz-Tocados JM, Peralta-Ramirez A, Rodríguez-Ortiz ME, et al. Dietary magnesium supplementation prevents and reverses vascular and soft tissue calcifications in uremic rats. Kidney Int. 2017;92:1084-99.

19. Bressendorff I, Hansen D, Schou M, Pasch A, Brandi L. The effect of increasing dialysate magnesium on serum calcification propensity in subjects with end stage kidney disease. Clin J Am Soc Nephrol. 2018;13: 1373-80.

20. Bressendorff I, Hansen D, Schou M, et al. Oral magnesium supplementation in chronic kidney disease stages 3 and 4: efficacy, safety, and effect on serum calcification propensity - a prospective randomized double-blinded placebo-controlled clinical trial. Kidney Int Reports. 2017;2:380-9.

21. Pasch A, Farese S, Gräber S, et al. Nanoparticle-based test measures overall propensity for calcification in serum. J Am Soc Nephrol. 2012;23(10):174452.

22. Peeters MJ, van Zuilen AD, van den Brand JAJG, et al. Nurse practitioner care improves renal outcome in patients with CKD. J Am Soc Nephrol. 2014 25:390-8.

23. Peeters MJ, van den Brand JA, van Zuilen AD, et al. Abdominal aortic calcification in patients with CKD. J Nephrol. 2017:30:109-18.

24. Van Zuilen AD, Bots ML, Dulger A, et al. Multifactorial intervention with nurse practitioners does not change cardiovascular outcomes in patients with chronic kidney disease. Kidney Int. 2012;82:710-7.

25. Van Zuilen AD, van der Tweel I, Blankestijn PJ, et al. Multifactorial approach and superior treatment efficacy in renal patients with the aid of nurse practitioners. Design of the MASTERPLAN study [ISRCTN73187232]. Trials. 2006;7:1-9.

26. Eckardt KU, Kasiske BL, Abboud O, et al. KDIGO (2009) KDIGO clinical practice guideline for the diag- nosis, evaluation, prevention, and treatment of chronic kidney disease-mineral and bone disorder (CKD-MBD). Kidney Int 2009;76:S1-2.

27. Kauppila LI, Polak JF, Cupples LA, Hannan MT, Kiel DP, Wilson PW. New indices to classify location, severity and progression of calcific lesions in the abdominal aorta: a 25-year follow-up study. Atherosclerosis. 1997;132:24550 .

28. van Buuren S, Oudshoorn K. MICE: multivariate imputation by chained equations in R. J Stat Softw. 2011:45:1-67.

29. Textor J, van der Zander B, Gilthorpe MS, Liśkiewicz M, Ellison GT. Robust causal inference using directed acyclic graphs: the R package "dagitty". Int J Epidemiol. 2016:45:1887-94.

30. R Core Team. R: a language and environment for statistical computing: $\mathrm{R}$ Foundation for Statistical Computing; 2019. 
31. Tzanakis I, Virvidakis K, Tsomi A, et al. Intra- and extracellular magnesium levels and atheromatosis in haemodialysis patients. Magnes Res. 2004;17: $102-8$.

32. Matias PJ, Azevedo A, Laranjinha I, et al. Lower serum magnesium is associated with cardiovascular risk factors and mortality in haemodialysis patients. Blood Purif. 2014;38:244-52.

33. Sakaguchi Y, Hamano T, Nakano C, et al. Association between density of coronary artery calcification and serum magnesium levels among patients with chronic kidney disease. PLoS One. 2016;11:e0163673.

34. Molnar AO, Biyani M, Hammond I, et al. Lower serum magnesium is associated with vascular calcification in peritoneal dialysis patients: a cross sectional study. BMC Nephrol. 2017;129:1-7.

35. Okamoto T, Hatakeyama S, Hosogoe S, et al. Proton pump inhibitor as an independent factor of progression of abdominal aortic calcification in patients on maintenance hemodialysis. PLoS One. 2018:13:1-14.

36. Tzanakis I, Pras A, Kounali D, et al. Mitral annular calcifications in haemodialysis patients: a possible protective role of magnesium. Nephrol Dial Transplant. 1997;12:2036-7.

37. Ishimura E, Okuno S, Kitatani K, et al. Significant association between the presence of peripheral vascular calcification and lower serum magnesium in hemodialysis patients. Clin Nephrol. 2007;68:222-7.

38. Tamura T, Unagami K, Okazaki M, Komatsu M, Nitta K. Serum magnesium levels and mortality in Japanese maintenance hemodialysis patients. Blood Purif. 2019;47:88-94

39. Adragao T, Pires A, Lucas $C$, et al. A simple vascular calcification score predicts cardiovascular risk in haemodialysis patients. Nephrol Dial Transplant. 2004;19:1480-8.

40. Wyatt CM, Drueke TB. Vascular calcification in chronic kidney disease: here to stay? Kidney Int. 2017;92:276-8.

41. Kircelli F, Peter ME, Sevinc Ok E, et al. Magnesium reduces calcification in bovine vascular smooth muscle cells in a dose-dependent manner. Nephrol Dial Transplant. 2012;27:514-21.

42. Montezano AC, Zimmerman D, Yusuf $\mathrm{H}$, et al. Vascular smooth muscle cell differentiation to an osteogenic phenotype involves TRPM7 modulation by magnesium. Hypertension. 2010;56:453-62.

43. De Oca AM, Guerrero F, Martinez-Moreno JM, et al. Magnesium inhibits wnt/b-catenin activity and reverses the osteogenic transformation of vascular smooth muscle cells. PLoS One. 2014;9:1-10.

44. Sakaguchi $Y$, Hamano T, Obi Y, et al. A randomized trial of magnesium oxide and oral carbon adsorbent for coronary artery calcification in predialysis CKD. J Am Soc Nephrol. 2019;30:1073-85.

\section{Publisher's Note}

Springer Nature remains neutral with regard to jurisdictional claims in published maps and institutional affiliations.

Ready to submit your research? Choose BMC and benefit from:

- fast, convenient online submission

- thorough peer review by experienced researchers in your field

- rapid publication on acceptance

- support for research data, including large and complex data types

- gold Open Access which fosters wider collaboration and increased citations

- maximum visibility for your research: over $100 \mathrm{M}$ website views per year

At $\mathrm{BMC}$, research is always in progress.

Learn more biomedcentral.com/submissions 